\title{
Effectiveness of Calcium Carbonate Whisker in Cementitious Composites
}

\author{
Mingli Cao ${ }^{1 *}$, Mehran Khan ${ }^{1}$, Shakeel Ahmed ${ }^{1}$ \\ 1 School of Civil Engineering, Dalian University of Technology, Linggong Road, Dalian 116024, Ganjingzi District, Liaoning, PR China \\ ${ }^{*}$ Corresponding author, e-mail: minglic@dlut.edu.cn
}

Received: 29 April 2019, Accepted: 16 January 2020, Published online: 11 February 2020

\begin{abstract}
Cementitious composites are porous material having complex structure system consist of hydration products, un-hydrated cement particles and pore solutions of various scales. Calcium carbonate whisker is a new type of low cost micro-scale filler fiber gaining popularity in the field of construction materials. However, addition of whisker has effect on physical, mechanical and microstructural characteristics of cementitious composites. Also, the low production cost of whisker will make the use of micro fiber more extensive in large scale construction projects. In this study, the effect of calcium carbonate whisker on physical, mechanical and microstructural properties of cementitious composites with different fiber contents are investigated. The fluidity, drying shrinkage, pore structure, impact resistance, compressive, flexural and splitting-tensile strength of whisker-mortar are considered. The scanning electron microscopy analysis is also performed to examine the microstructural and toughening mechanism of whisker reinforced composites. It was concluded that the addition of calcium carbonate whisker up to $10 \%$ improves the physical and mechanical properties of cementitious composites and is suggested to be the optimize content. The calcium carbonate whisker also resists the crack propagation at micro scale and showed the toughening mechanism with better interfacial properties between whisker and matrix.
\end{abstract}

\section{Keywords}

calcium carbonate whisker, microfiber, low cost, mechanical properties, scanning electron microscopy

\section{Introduction}

The traditional cement based materials are very brittle and have a low tensile strength $[1,2]$. The different commercial fibers are used as reinforcement in cementitious composites to reduce the brittleness under static and dynamic loading [3-9]. On the other hand, high production cost of fiber in large scale construction had limited the use of fiber in cementitious composites [1]. Therefore, the fibers having low cost and improved mechanical properties will be helpful to reduce the overall production cost of cementitious composites at large scale construction project.

Calcium carbonate whisker is a micro-scale fiber having high aspect ratio, elastic modulus and strength and also helps in resisting the cracks at micro level [10]. Calcium carbonate whisker is used as filler in wide range of applications $[11,12]$. Calcium carbonate whisker has a low cost of about \$200 per ton which is helpful to reduce the overall production cost of large scale construction projects [13]. Calcium carbonate whisker has the simple production processes and low production cost as compared to that of other fibers as shown in Table 1 [14]. The low strength and brittleness of cementitious composites had limited its use in many construction applications especially in China [15-17]. The fiber toughening plays an important role in reducing the brittleness of cementitious composites $[18,19]$. Therefore, calcium carbonate whisker is a good choice to reduce the brittleness and with low production cost of cementitious composites.

Table 1 Production cost of different fibers [14]

\begin{tabular}{lccc}
\hline Fibers & $\begin{array}{c}\text { Production } \\
\text { Cost }(\$ / \text { Ton })\end{array}$ & $\begin{array}{c}\text { Density } \\
\left(\mathrm{g} / \mathrm{cm}^{3}\right)\end{array}$ & $\begin{array}{c}\text { Tensile } \\
\text { strength }(\mathrm{MPa})\end{array}$ \\
\hline $\mathrm{CaCO}_{3}$ whisker & $200-230$ & 2.86 & $>3000$ \\
PET fiber & $300-400$ & 1.36 & $>700$ \\
Carbon fiber & $>20,000$ & 1.76 & $>3500$ \\
PP fiber & $1200-2500$ & 0.9 & $>684$ \\
PVA fiber & $800-1500$ & 1.29 & $>1100$ \\
Steel fiber & $590-750$ & 7.8 & $>2000$ \\
\hline
\end{tabular}


Table 2 Chemical Composition of calcium carbonate whiskers

\begin{tabular}{lccccccccc}
\hline Components & $\mathrm{CaO}$ & $\mathrm{CO}_{2}$ & $\mathrm{MgO}$ & $\mathrm{SO}_{3}$ & $\mathrm{SiO}_{2}$ & $\mathrm{Al}_{2} \mathrm{O}_{3}$ & $\mathrm{Fe}_{2} \mathrm{O}_{3}$ & $\mathrm{SrO}_{2}$ & $\mathrm{Cr}_{2} \mathrm{O}_{3}$ \\
\hline Content (\%) & 54.93 & 42.07 & 2.14 & 0.31 & 0.29 & 0.11 & 0.07 & 0.05 & 0.03 \\
\hline
\end{tabular}

\section{Research significance}

The addition of $\mathrm{CaCO}_{3}$ whiskers into cement-based materials will change the pore structure of the matrix and also effect the physical and mechanical properties. So, it is of great significance to study the influence of whiskers on the pore structure parameters and characteristics of cement paste. It also provides an important theoretical basis for further mechanism analysis of whiskers improving the properties of cement-based materials. But compared with pure cement paste, the matrix interface and structure level of mortar is more complex and the application scope is more extensive. The mechanical and microstructure of cementitious composites are influence size, type, content and distribution of reinforcing additives $[9,20-23]$ as well as interfacial bond between matrix and reinforcing material $[10$, 24-26]. Therefore, the effect of $\mathrm{CaCO}_{3}$ whisker on microstructural and mechanical properties of cement mortar is also necessary to study which will provide a good foundation for the research and application of whisker in cementitious composites. In this research, calcium carbonate whiskers are added into cement mortar having different whisker content, i.e. $0 \%, 5 \%, 10 \%$ and $20 \%$, by cement mass. The influence of $\mathrm{CaCO}_{3}$ whiskers (CCW) on the physical and mechanical properties of cement mortar is investigated. In terms of physical properties, the fluidity, drying shrinkage and pore structure of $\mathrm{CCW}$ mortar are considered. For mechanical properties, the impact resistance, compressive, flexural and splitting-tensile strength of whisker-mortar is mainly evaluated for optimum content of whisker. The microstructural and toughening mechanism of whisker is also studied using scanning electron microscopy analysis.

\section{Experimental plan}

\subsection{Raw materials}

The Ordinary Portland Cement and standard sand are used in this research. The calcium carbonate whisker is shown in Fig. 1(a) and chemical composition is shown in Table 2. The $\mathrm{CaO}$ and $\mathrm{CO}_{2}$ is about $97 \%$ of the total mass in the chemical composition of $\mathrm{CaCO}_{3}$ whiskers. So, the main chemical composition of calcium carbonate whiskers is $\mathrm{CaCO}_{3}$ with high purity. The crystal structure of calcium carbonate whiskers was determined by XRD-6000 X-ray diffractometer. Fig. 1(b) demonstrates the XRD pattern of calcium carbonate whiskers. The main crystal form

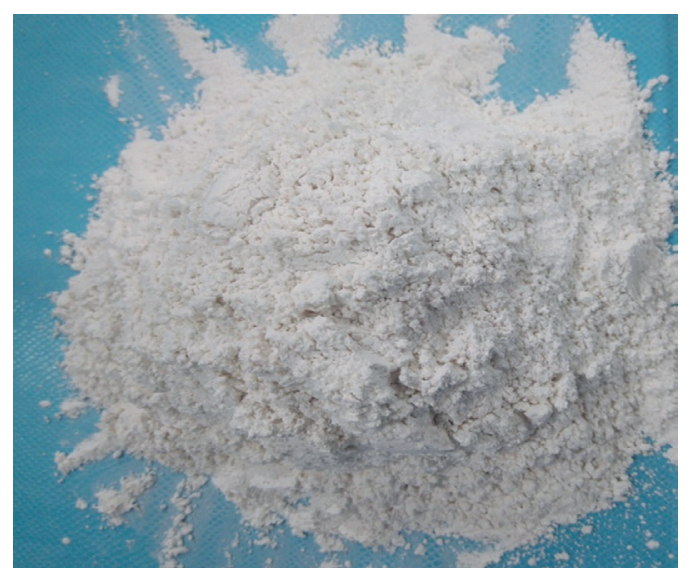

(a)



(b)

Fig. 1 Calcium carbonate whisker: (a) Physical appearance; (b) XRD pattern

of calcium carbonate whisker is aragonite phase, so the whisker is aragonite type calcium carbonate whisker. At the same time, according to the intensity of diffraction peak, calcium carbonate whiskers have high purity and crystallinity. The micro-morphology of calcium carbonate whiskers was observed and shown in Fig. 2. It can be seen that aragonite-type calcium carbonate whiskers have needle-like structure.

\subsection{Specimens preparation}

Calcium carbonate whiskers added to cement mortar with content of $5 \%, 10 \%$ and $20 \%$, by cement mass. The mortar mix design ratio for cement, sand and water was 1, 3 and 0.5 . The specimens with size of $40 \mathrm{~mm} \times 40 \mathrm{~mm} \times 160 \mathrm{~mm}$, $40 \mathrm{~mm} \times 40 \mathrm{~mm} \times 40 \mathrm{~mm}$ and $152 \mathrm{~mm} \times 63.5 \mathrm{~mm}$ were cast. 




Fig. 2 SEM of calcium carbonate whisker

The specimens were maintained under the specified conditions according to the GB/T50081 [27] standard, and finally tested at their specified age. For mercury intrusion porosimetry test, calcium carbonate whiskers with different content, i.e. $0 \% \sim 20 \%$ were mixed into cement paste. The prepared cement paste samples were cured in water at $(20 \pm 2){ }^{\circ} \mathrm{C}$ with relative humidity over $90 \%$ ) for specified days. The $40 \mathrm{~mm} \times 40 \mathrm{~mm} \times 160 \mathrm{~mm}$ specimens were used for compressive strength and flexural strength tests. The samples of size $40 \mathrm{~mm} \times 40 \mathrm{~mm} \times 40 \mathrm{~mm}$ specimens were used for splitting tensile strength tests and $152 \pm 3 \mathrm{~mm} \times 63.5 \pm 3 \mathrm{~mm}$ specimens were used for impact resistance tests. The fragments samples after the test were soaked in absolute ethanol to stop their hydration and their microstructure and morphology were analyzed by scanning electron microscopy.

\subsection{Test methods}

The standard GB/T2419 [28] was followed for determining the fluidity test of cement mortar. The cement mortar drying shrinkage test was carried out as per JGJ/T70 [29] standard. The vertical mortar shrinkage meter was used in this study. The precision was $0.01 \mathrm{~mm}$. The specimens of size $40 \mathrm{~mm} \times 40 \mathrm{~mm} \times 160 \mathrm{~mm}$ were used. The length of the specimens was measured on the $0 \mathrm{th}, 7 \mathrm{th}, 14 \mathrm{th}$, 21st, 28th, 56th and 90th days. The cement mortar drying shrinkage value was computed as per to Eq. (1).

$S_{t}=\frac{L_{0}-L_{t}}{L-L_{d}}$

Where, $S_{t}$ is the dry shrinkage value of the specimens on the $\mathrm{t}$ day ( 7 days, 14 days, 21 days, 28 days, 56 days and 90 days); $L_{0}$ is the length of the specimens after 7 days $(\mathrm{mm}) ; L_{t}$ is the measured length $(\mathrm{mm})$ of the mortar specimens on the " $t$ " day (7 days, 14 days, 21 days, 28 days, 56 days and 90 days); $L$ is the length of the specimens (mm); $L_{d}$ is the sum of the length of the two shrinkage heads set at the specimens (mm). The average values of three specimens were taken for each test. The AUTOPORE 9500 mercury intrusion meter was used to test mercury intrusion porosimetry of cement paste.

The testing machine WHY type computer controlled full automatic press was used and compressive strength test was performed as per GB/T17671 [30] standard. During the whole testing process, it is loaded uniformly at a rate of $2400 \mathrm{~N}(+200 \mathrm{~N} / \mathrm{s})$. The average values of six specimens were taken for compressive strength. The flexural strength test method was carried out as per GB/T17671 [30] standard. The specimen size of $40 \mathrm{~mm} \times 40 \mathrm{~mm} \times 160 \mathrm{~mm}$ was used. The WDW-50 computer-controlled electronic UTM was selected for the bending test. The rate of loading was $0.2 \mathrm{~mm} / \mathrm{min}$. The average value of three specimens was taken for each group. The CECS13:89 [31] standard was used for splitting tensile strength test to evaluate the tensile properties of the specimens. The size of the specimens was $40 \mathrm{~mm} \times 40 \mathrm{~mm} \times 40 \mathrm{~mm}$ and the testing equipment was WDW-50 computer controlled electronic UTM. The rate of loading was $0.2 \mathrm{~mm} / \mathrm{min}$. The calculated average values of three specimens were taken. The impact resistance test was performed as per ACI544-2R [32] recommended method, i.e. drop weight method. The test setup is mainly consist of a $4.5 \mathrm{~kg}$ compact steel impact hammer, a $63.5 \mathrm{~mm}$ diameter hard steel ball and protective devices, brackets, baffles and bottom plates. The specimens used in the test are cylindrical specimens. The impact number at first/initial crack $\left(N_{1}\right)$ and at final failure of specimens $\left(N_{2}\right)$ was observed. The total impact energy absorption and the impact energy absorption after initial crack, i.e. post crack energy absorption are calculated according to Eq. (2) and Eq. (3), respectively.

$$
\begin{aligned}
& W=N_{2} m g h \\
& \Delta W=\Delta N \times m g h
\end{aligned}
$$

Whereas, $W$ is the total impact energy absorption by the sample up to the failure (J); $N_{2}$ is the number of impact times until the specimen failure; $\Delta W$ is the impact energy absorption by sample after initial crack; $\Delta N$ is the difference between the number of impact damage times of the specimen after initial crack; $m$ is the weight of the steel hammer $(\mathrm{kg}) ; h$ is heavy hammer drop height $(\mathrm{m}) ; g$ is the gravity acceleration $(9.8 \mathrm{~N} / \mathrm{kg})$. The QUANTA-450 machine was used for SEM to observe the microstructure and morphology of specimens. 


\section{Results and discussion}

\subsection{Effect calcium carbonate whisker on physical properties of mortar}

\subsubsection{Fluidity of whisker mortar}

The influence of whiskers on the fluidity of cement mortar was analyzed using plain mortar as reference sample. The fluidity of all mixes is shown in Fig. 3. The flowability diameter of cement mortar reduces with increase in calcium carbonate whisker percentage which shows that the fluidity of mortar decreases. When the whisker content is $5 \%$ and $10 \%$, the fluidity was reduced by $2.3 \%$ and $3.7 \%$, respectively, as compared to that of plain mortar. With further increase in whisker content, the fluidity decreases significantly. When the whisker content was $20 \%$, the fluidity of mortar was decreased by $12 \%$, respectively, than that of plain mortar. The analysis showed that the fluidity of mortar does not effect too much up to $10 \%$ whisker content; beyond this the fluidity decrease with increase in whisker content. This is because whiskers have unique structure and performance characteristics. The ultra-fine needle-like structure and high elastic modulus make the whiskers evenly distributed in the matrix. In addition, the needle-like structure of the whisker reduces the flow and shear resistance in the matrix. However, excessive whisker content will significantly increase the surface area and distribution density of whiskers per unit volume resulting in increased amount of cement required to cover the whisker surface area.

\subsubsection{Drying shrinkage of whisker mortar}

The drying shrinkage values of mortar specimens at different ages were measured and the experimental results are shown in Fig. 4. It may be noted that the dry shrinkage value of mortar specimens with different whisker content increases with age. Compared with the plain sample, the dry shrinkage value of the specimen does not change significantly at $5 \%$ whisker content. When the whisker content reaches $10 \%$, the early dry shrinkage value of the specimen was slightly larger than that of the plain sample. Furthermore, after 28 days, the dry shrinkage value was basically the same as that of the plain sample. The dry shrinkage value increases with the further increase in whisker content. When the whisker content is $20 \%$, the dry shrinkage value is significantly higher than that of the plain sample. It may be noted that the incorporation of whiskers does not significantly improve the dry shrinkage resistance of cement mortar. On the other hand, excessive amount of whiskers will increase the dry shrinkage value.
Although whiskers have fibrous structure, high aspect ratio and elastic modulus which can theoretically limit the plastic shrinkage of the matrix to a certain extent in its scale range. The addition of whiskers may cause fine changes in the pore structure of mortar, thus counteracting the contribution of whiskers to reducing the dry shrinkage of the matrix. In addition to this, because of the large specific surface area of whiskers excessive amount of whiskers will lead to more bubbles resulting in an increase in porosity. Also, it decreases the matrix compactness resulting in an increase in drying shrinkage.

\subsubsection{Pore Structure of whisker cement paste}

The pore structure of cement paste after 28 days with different calcium carbonate whisker content was studied by mercury intrusion test. Table 3 demonstrates the pore structure parameters of cement paste. It may be noted that



Fig. 3 Fluidity of mortar with various whisker content

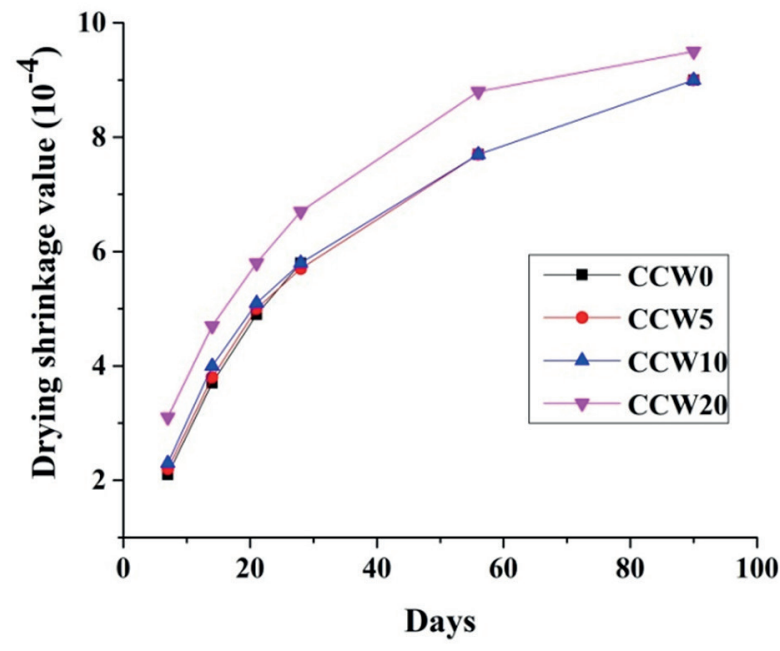

Fig. 4 Drying shrinkage of mortar with various whisker content 
Table 3 Parameters of pore structure in whisker cement paste

\begin{tabular}{|c|c|c|c|c|c|c|}
\hline Mix & Content (\%) & $\begin{array}{l}\text { Total Mercury Intake } \\
\text { Volume }(\mathrm{mL} / \mathrm{g})\end{array}$ & $\begin{array}{c}\text { Total Pore Surface } \\
\text { Area }\left(\mathrm{m}^{2} / \mathrm{g}\right)\end{array}$ & $\begin{array}{c}\text { Average Pore } \\
\text { Diameter (nm), }\end{array}$ & $\begin{array}{l}\text { Median Pore } \\
\text { Diameter (nm) }\end{array}$ & Porosity (\%) \\
\hline CCW0 & 0 & 0.10 & 7.52 & 50.86 & 64.19 & 17.98 \\
\hline CCW10 & 10 & 0.11 & 9.74 & 42.43 & 61.45 & 19.27 \\
\hline CCW20 & 20 & 0.11 & 8.41 & 50.86 & 63.21 & 19.71 \\
\hline
\end{tabular}

the porosity of cement paste increases with increase in whisker content. The porosity of matrix of CCW10 and CCW20 was increased by $7 \%$ and $9 \%$, respectively, as compared to that of plain sample. The mean and median pore sizes are important parameters to characterize the average pore sizes and their sizes also affect the comprehensive properties of composites. When the whisker content is less than $10 \%$, the average pore size and volume median pore size are not significantly increased. The average pore size and volume median pore size of CCW10 were reduced by $17 \%$ and $4 \%$, respectively, than that of CCW0. The appropriate amount of whisker can fill the cement paste compactly up to a certain extent which may be helpful for improving the properties of the matrix.

\subsection{Effect calcium carbonate whisker on mechanical properties of mortar}

\subsubsection{Compressive strength}

Fig. 5 shows the effect of different CCW content on the compressive strength of cement mortar. It may be noted that the 3 days and 28 days compressive strength of the specimens are improved by addition of whiskers. When the whisker content is $5 \%, 10 \%$ and $20 \%$, the 3 days compressive strength was increased by $19 \%, 15 \%$ and $19 \%$, respectively, as compared with that of plain sample. The compressive strength of the samples with $10 \%$ whisker was

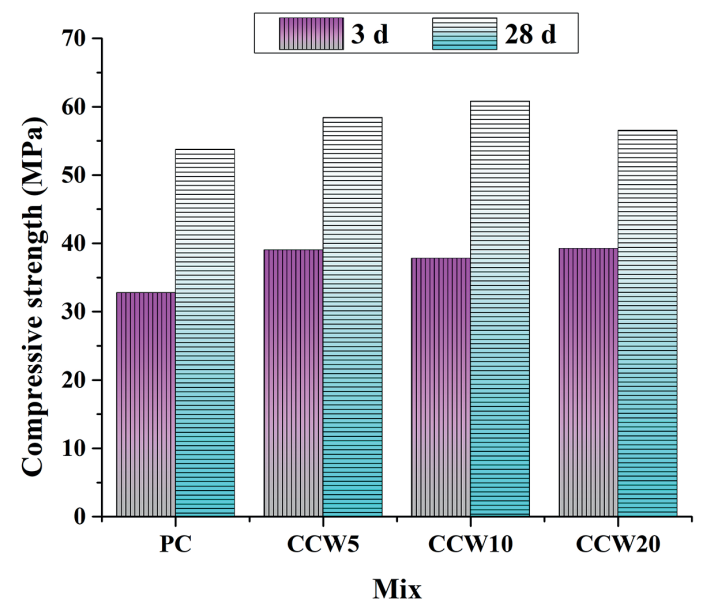

(a) the best. The compressive strength of CCW10 was $13 \%$ higher, as to that of plain specimen at 28 days. At early stage, the whisker reinforcement and toughening was particularly prominent due to its unique needle-like structure and excellent physical and mechanical properties. In the later stage, the hydration products in matrix are more compact and the rate of increase in strength of matrix was relatively higher than early age strength. On the contrary, with the excessive amount of whisker more interfacial defects and the uneven dispersion of whiskers will be more prominent which affect the enhancement effect of whiskers. Therefore, for the compressive strength of mortar, the optimize whisker content is $10 \%$, by cement mass.

\subsubsection{Flexural strength}

The flexural strength of mortar with various whisker contents is shown in Fig. 6. It may be noted that the flexural strength of mortar with whisker was obviously higher than that of plain sample. The flexural strength of mortar was increased up to addition of $10 \%$ whisker content and then decrease with increase in whisker content to $20 \%$. The flexural strength at 3 days was increased by $19 \%, 28 \%$ and $24 \%$ with the addition of $5 \%, 10 \%$ and $20 \%$ whisker content, respectively, than that of plain sample. The flexural strength of CCW20 was decreased, but it is still higher than that of the plain specimen without whisker at

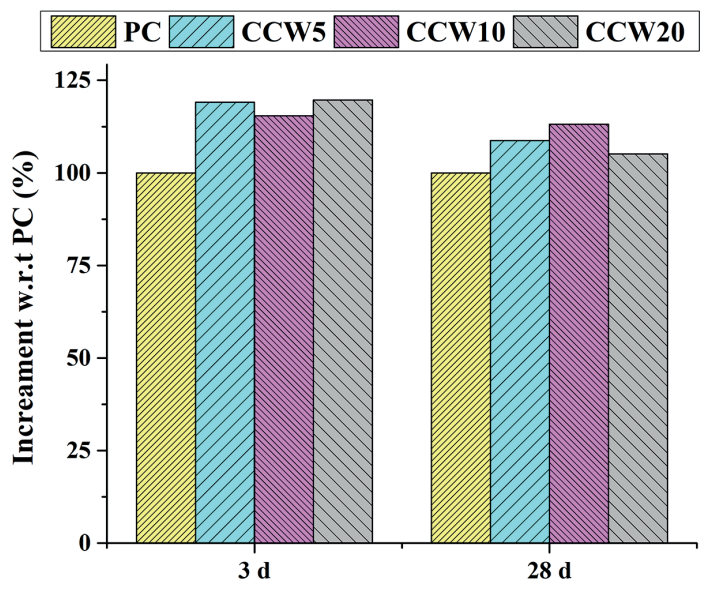

(b)

Fig. 5 Compressive properties: (a) Strength; (b) Percentage increase in strength w.r.t PC 
28 days. The increment in the flexural strength of CCW10 was $6 \%$, than that of plain sample. Therefore, comprehensive analysis shows that when the content of calcium carbonate whisker is $10 \%$, the mortar flexural strength demonstrates the best enhancement effect. This may be due to the crack bridging effect provided by calcium carbonate whisker at micro scale.

\subsubsection{Splitting tensile strength}

The addition of calcium carbonate whisker improves the splitting tensile strength of cement mortar specimens (refer Fig. 7). The splitting tensile strength of CCW10 had the maximum value of $4.1 \mathrm{MPa}$ which is $27 \%$ higher, than that of the pure cement mortar specimens. However, the strength of the specimens decreases slightly after further addition of higher whisker content. The splitting tensile



(a) strength of CCW20 is reduced, but is still higher than that of the pure cement mortar specimens. This may be due to random distributed of calcium carbonate whisker in the cement mortar matrix. The larger aspect ratio and the higher elastic modulus of the whiskers provide the resistance to internal tensile stress significantly ultimately improved the strength of the mortar matrix. In addition to this, whisker pull-out and micro-crack bridging can effectively consume destructive energy, slow down crack growth and play a significant role in enhancing the tensile properties of the matrix.

\subsubsection{Impact resistance}

The impact test results of whisker reinforced cement mortar are shown in Fig. 8 and Fig. 9. The effect of calcium carbonate whisker on the impact resistance of mortar was

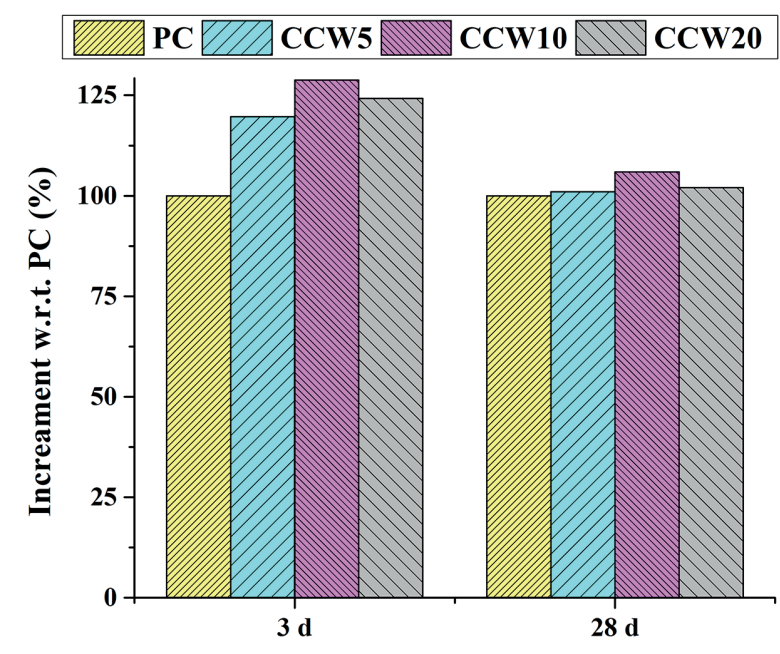

(b)

Fig. 6 Flexural properties: (a) Strength; (b) Percentage increase in strength w.r.t PC

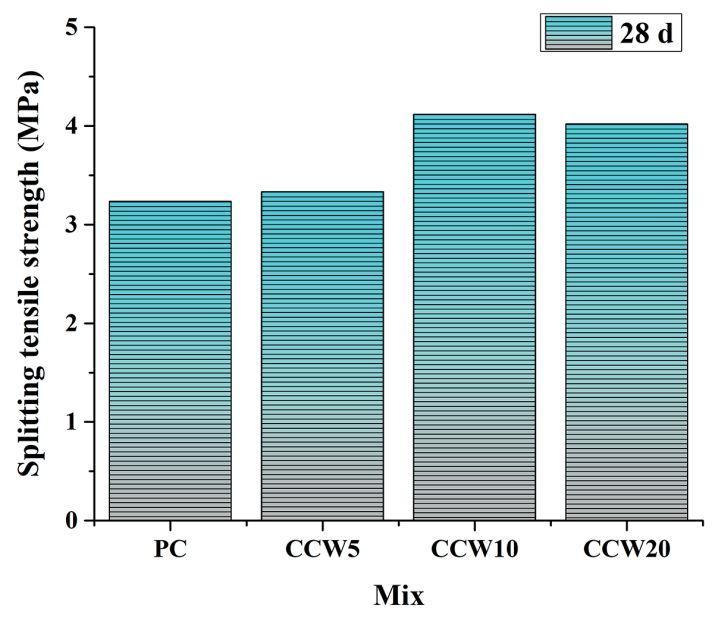

(a)

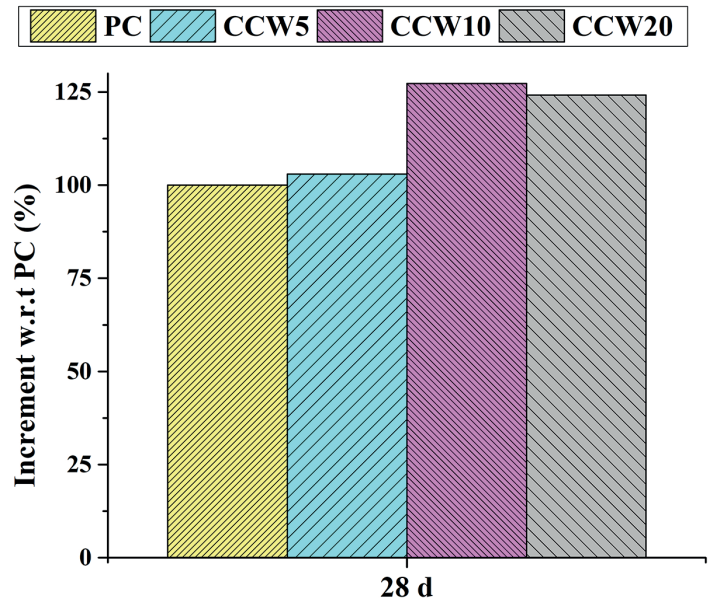

(b)

Fig. 7 Splitting tensile properties: (a) Strength; (b) Percentage increase in strength w.r.t PC 


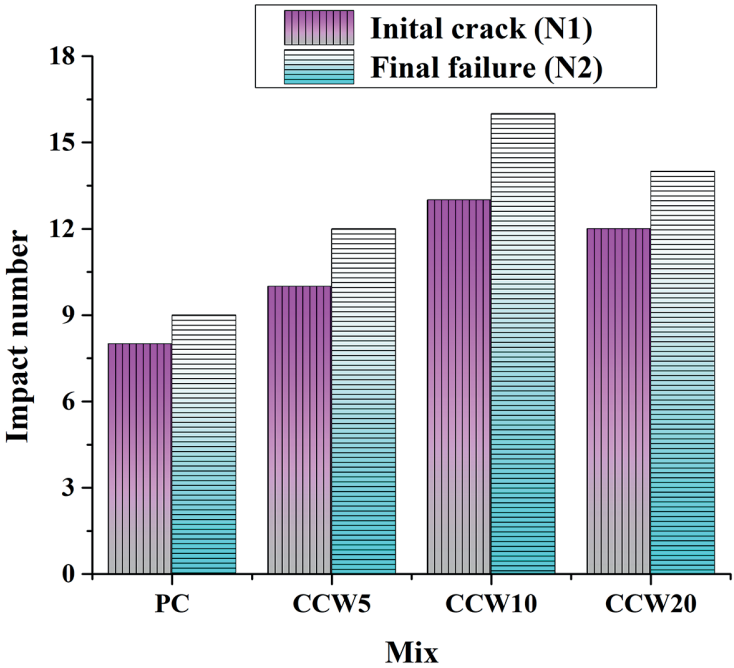

(a)

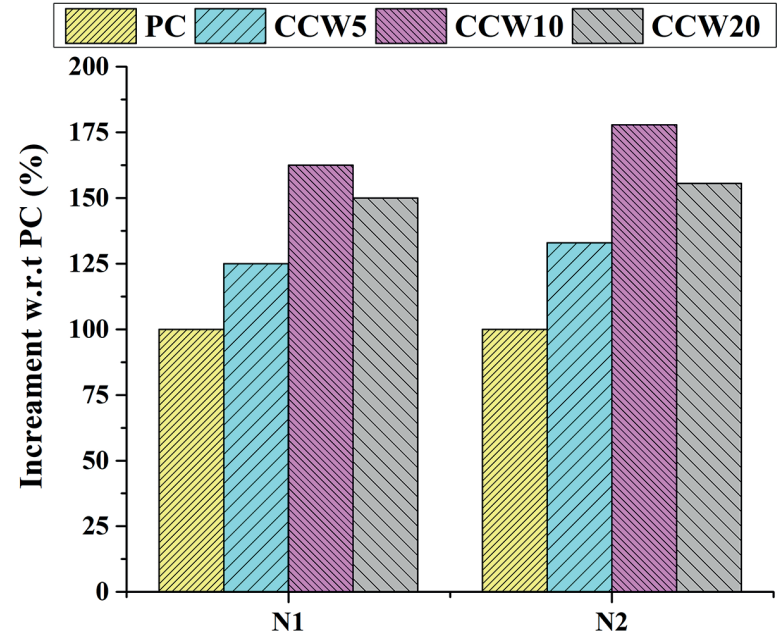

(b)

Fig. 8 Impact properties: (a) Impact number; (b) Percentage increase in strength w.r.t PC



(a)

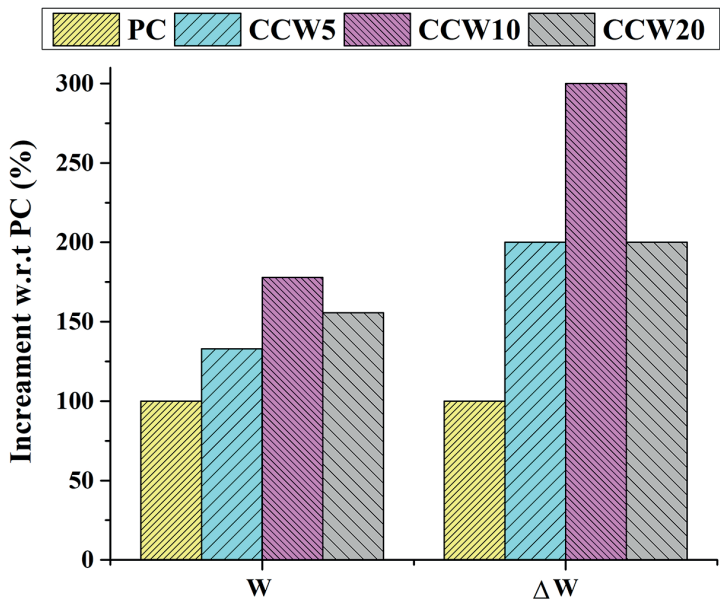

(b)

Fig. 9 Impact properties: (a) Impact energy; (b) Percentage increase in strength w.r.t PC

evaluated by impact number and impact energy absorbed. The increase in addition of calcium carbonate whisker content shows an increasing trend in the impact number of initial crack and final failure of cement mortar specimens. The addition of $10 \%$ whisker content showed higher impact number than that of other composites. The impact number of initial crack and final failure of CCW10 are improved by $62 \%$ and $77 \%$, respectively, as compared to that of plain sample. The impact number was reduced with further increase in whisker content beyond $10 \%$. At the same time, it was found that the number of impact load had not been significantly increased after initial cracking. Therefore, the incorporation of whiskers improves impact resistance of the matrix before initial crack, but does not significantly improve the capability of specimens to continue resistance against impact load after initial crack.
Additionally, the impact toughness of specimens can also be reflected by the impact energy. The impact energy absorbed after initial cracking (post crack energy absorption) is used as the evaluation index to measure the impact resistance of specimens. From Fig. 9, it may be noted that the total impact energy absorption during the failure process of the specimens had been significantly increased with the increase in whisker content. The trend of the increase in impact energy absorption before initial crack is more significant than after initial crack. The impact energy absorption by the specimens after initial crack showed the peak value with $10 \%$ whisker content. However, the impact energy absorbed by the specimens after initial crack did not increase considerably which indicated that the toughness of the specimens after initial cracking did not improve significantly with addition of whisker. 


\section{Microstructure analysis of calcium carbonate whisker reinforced cement mortar}

The SEM image of whisker reinforced cement mortar specimen is shown in Fig. 10. It can be clearly found that calcium carbonate whiskers are needle-like structure which are encapsulated by cement paste, and have a good bonding property with the matrix (Refer Fig. 10(a)). As a micro fiber, calcium carbonate whiskers are evenly distributed in the matrix of mortar and show a random fiber distribution as shown in Fig. 10(b). The toughening mechanism of whiskers on composites can be summarized as three mechanisms, i.e. crack deflection, pull-out effect and crack bridging as shown in Fig. 11. For cement mortar, the internal pore and interface of matrix are more complex than pure cement The basic characteristics of whisker, the range of whisker content, distribution and the bonding status with matrix interface also directly affect the role of strengthening and toughening. When the cement mortar matrix is subjected to external loads, its failure process is mainly divided into micro-crack generation, crack

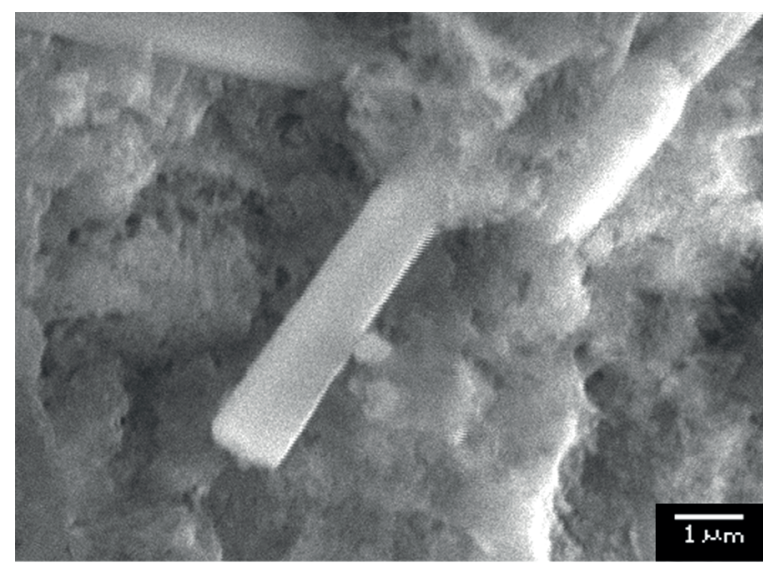

(a)

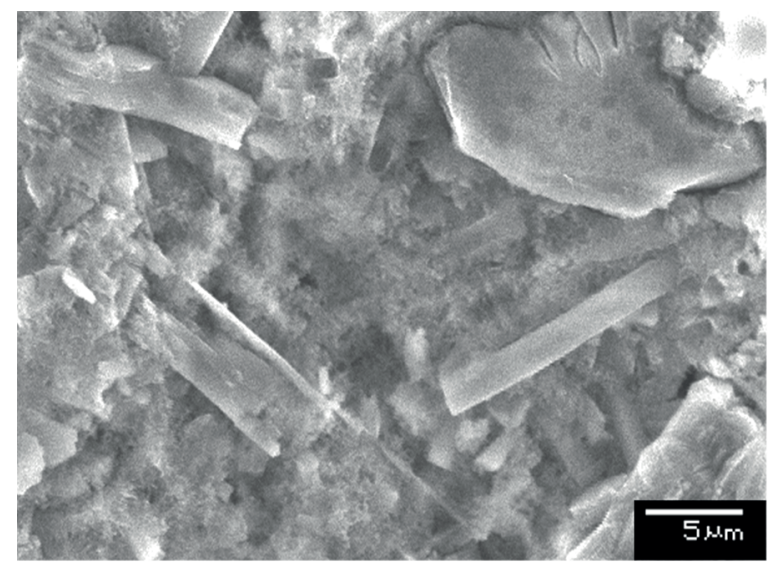

(b)

Fig. 10 SEM images of whisker-reinforced cement mortar: (a) whisker bonding; (b) whisker uniform distribution

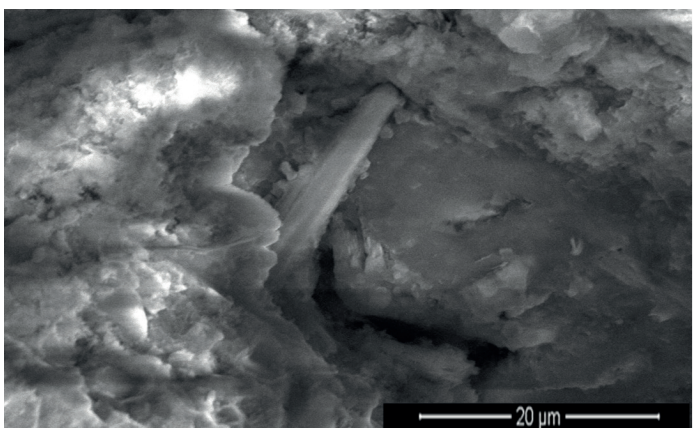

(a)

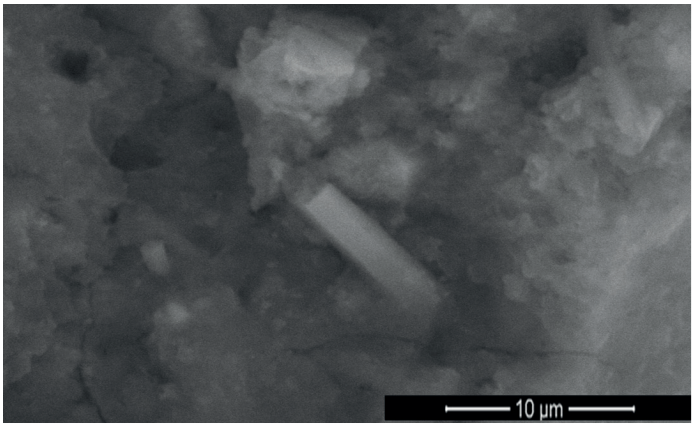

(b)



(c)

Fig. 11 SEM images of crack resistance and toughening mechanisms of whiskers: (a) crack deflection; (b) whisker pull-out; (c) crack bridging

propagation and matrix instability failure. The addition of whisker can prevent and slow down the matrix failure process within its scale, so as to achieve the purpose of strengthening and toughening.

In this study, crack deflection, pull-out effect and crack bridging are the three main ways of whisker toughening composites which are also verified in cement mortar system. As shown in Fig. 11, they play an important role in different regions of matrix, stress stage and stress environment. From Fig. 11(a) it may be noted that the crack will deflect along the whisker-matrix interface which increases the crack propagation path and consumes more destructive energy. With the continuous increase in internal tensile stress and the further expansion of crack size, the shear stress at the whisker-matrix interface will also increase at 
the crack tip ultimately results in whisker pullout as shown in Fig. 11(b). In that region, the number of whisker pull-out increases gradually and the pull-out effect plays a dominant role in the final stage of crack growth. In the process of whisker pull-out, each whisker can be regarded as a tiny "energy dissipating mechanism" which leads to the energy dissipation of crack propagation along with the dissociation and friction of the interface between whisker and cement matrix. When the whisker slides it leads towards the stress relaxation at the crack tip.

The stress relaxation slows down the crack propagation process. It is concluded that whisker bridging plays a major role when the initial tensile or compressive stresses are applied to the interior of mortar. In the crack area, whisker can effectively relieve the stress concentration at the crack-tip and delay the further propagation of microcracks by applying closed stress at both ends of the crack (refer Fig. 11(c)). When the whisker is extended to a small angle, it is usually difficult to cross the whisker in the initial direction. In addition to this, different toughening mechanisms are not isolated but closely related. For example, whisker pull-out is often accompanied by crack bridging. When the crack size is very small bridging plays a leading role. With the gradual expansion of crack size, the shear stress on the whisker at the crack tip is greater and the pull-out effect becomes the main toughening mechanism. However, whiskers play a complex role in strengthening and toughening the matrix structure. So, the main toughening mechanisms will vary under different conditions and largely depend on the characteristics of whiskers and the bonding between whiskers and matrix interface. The interfacial shear strength directly affects the mode of strengthening and toughening. When the interfacial shear strength between whisker and matrix is small and the whisker strength is high, the pull-out effect is remarkable. Moreover, when the interfacial shear strength increases, the pull-out effect decreases and the whisker break without pull-out effect under tensile stress. It can be seen that the interfacial properties of whisker and matrix play an important role in strengthening and toughening effect. The whisker strengthening effect can reach the best only when the interfacial bonding strength is appropriate.

\section{Conclusions}

In this study, calcium carbonate whiskers are mixed into cement mortar with different dosages to study their effects on the physical and mechanical properties. The microstructure and morphology of cement mortar are observed by scanning electron microscopy and the mechanism of whisker reinforced cement mortar is analyzed and discussed. Following conclusions are made:

- The fluidity of cementitious composites decreases with increase in whisker content. The fluidity of whisker reinforced mortar reduced up to $34 \%$, as compared to that of plain mix.

- The dry shrinkage value of cement mortar specimens increases with increase in whisker content. The drying shrinkage of CCW5 and CCW10 specimens is not significantly improved. After 28 days, the drying shrinkage value of mortar specimens is basically the same as that of plain specimens. With the further increase of whisker content, the drying shrinkage value also increases. When the whisker content is $20 \%$, the drying shrinkage value is significantly higher than that of plain specimens.

- According to mercury injection test, the porosity of cement-paste increases with the increase in $\mathrm{CaCO}_{3}$ whisker content. The increase of voids is more significant with further increase in whisker content. The addition of $10 \%$, whisker content indicates that the appropriate whisker content can play a filling and compacting role up to a certain extent.

- Calcium carbonate whisker can improve the 3 days and 28 days compressive strength of cement mortar up to $19 \%$ and $13 \%$, respectively, as compared to that of plain sample. The optimize whisker content for 28 days compressive strength is $10 \%$, by cement mass.

- The flexural strength of the cement mortar with whisker is enhanced significantly. The flexural strength increases first and then decreases with increase in whisker content. The enhancement effect is the best at 3 days with $10 \%$ whisker content. The flexural strength of whisker reinforced cement mortar with $10 \%$ content is improved by $6 \%$, as to that of plain specimen at 28 days. With further increase in the whisker content beyond $10 \%$ content the flexural strength decreases.

- The splitting tensile strength of whisker reinforced cementitious composites is also improved. When the content of whisker is $10 \%$, the splitting tensile strength of the specimens is increased up to $27 \%$, than that of the pure cement mortar specimen.

- The addition of calcium carbonate whisker can enhanced the impact resistance of cementitious composites up to a certain extent. The impact number times and impact energy absorption are increased at 
$10 \%$ whisker content. However, the ability to resist continuously against impact load after the initial cracking of the matrix is not enhanced considerably.

- The SEM analysis shows three mechanisms, i.e. crack deflection, pull-out effect and crack bridging which can effectively consume destructive energy, alleviate stress concentration, restrict the propagation process of micro cracks and play a reinforcing and toughening role. For mortar matrix, whisker is mainly pulled out and this toughening mechanism plays a dominant role. At the same time, the interfacial properties between whiskers and mortar matrix are important factors affecting the toughening effect.

\section{References}

[1] Cao, M., Li, L., Zhang, C., Feng, J. "Behaviour and damage assessment of a new hybrid-fibre-reinforced mortar under impact load", Magazine of Concrete Research, 70(17), pp. 905-918, 2017. https://doi.org/10.1680/jmacr.16.00536

[2] Yang, Y., Fu, S., Li, X. "Mechanical attributes of uniaxial compression for calcium carbonate whisker reinforced oil well cement pastes", Advances in Materials Science and Engineering, Article ID $2939057,2017$.

https://oi.org/10.1155/2017/2939057

[3] Chiranjeevi Reddy, K., Subramaniam, K. V. L. "Experimental investigation of crack propagation and post-cracking behaviour in macrosynthetic fibre reinforced concrete", Magazine of Concrete Research, 69(9), pp. 467-478, 2017. https://doi.org/10.1680/jmacr.16.00396

[4] Hao, Y., Hao, H. "Mechanical properties and behaviour of concrete reinforced with spiral-shaped steel fibres under dynamic splitting tension", Magazine of Concrete Research, 68(21), pp. 1110-1121, 2016.

https://doi.org/10.1680/jmacr.15.00372

[5] Lee, J.-H., Yoo, D.-Y., Yoon, Y.-S. "Mechanical behaviour of concrete with amorphous metallic and steel fibres", Magazine of Concrete Research, 68(24), pp. 1253-1264, 2016.

https://doi.org/10.1680/jmacr.15.00493

[6] Soe, K. T., Zhang, Y. X., Zhang, L. C. "Material properties of a new hybrid fibre-reinforced engineered cementitious composite", Construction and Building Materials, 43, pp. 399-407, 2013. https://doi.org/10.1016/j.conbuildmat.2013.02.021

[7] Tran, T. K., Kim, D. J. "Investigating direct tensile behavior of high performance fiber reinforced cementitious composites at high strain rates", Cement and Concrete Research, 50, pp. 62-73, 2013. https://doi.org/10.1016/j.cemconres.2013.03.018

[8] Xu, Z., Hao, H., Li, H. N. "Experimental study of dynamic compressive properties of fibre reinforced concrete material with different fibres", Materials \& Design, 33, pp. 42-55, 2012. https://doi.org/10.1016/j.matdes.2011.07.004
- The $10 \%$ whisker content, by cement mass, is suggested to be the optimize content for physical and mechanical properties of cementitious composites.

\section{Acknowledgements}

The authors would like to acknowledge the support of this work by the Natural Science Foundation of China under Grant No. 51678111 and No. 51478082. The financial support from China Scholarship Council (CSC) for PhD studies of Engr. Mehran Khan at Dalian University of Technology, China is gratefully acknowledged. The authors are also thankful to Dr. Cao Mingli research group for their help during the lab work.

[9] Shiri, S., Abbasi, M. H., Monshi, A., Karimzadeh, F. "A study on mechanical and physical properties of monocalcium aluminate cement reinforced with nano- $\mathrm{SiO}_{2}$ particles", Composites Part B: Engineering, 56, pp. 30-33, 2014. https://doi.org/10.1016/j.compositesb.2013.08.057

[10] Li, M., Yang, Y., Liu, M., Guo, X., Zhou, S. "Hybrid effect of calcium carbonate whisker and carbon fiber on the mechanical properties and microstructure of oil well cement", Construction and Building Materials, 93, pp. 995-1002, 2015. https://doi.org/10.1016/j.conbuildmat.2015.05.056

[11] Qiu, H. H., Luo, K. B., Li, H. P. "Progress on preparation and application of calcium carbonate whisker", Advanced Materials Research, 1094, pp. 113-117, 2015.

https://doi.org/10.4028/www.scientific.net/AMR.1094.113

[12] Sohrabi, M., Shirmohammadi, H., Hamedi, G. H. "Investigating the Effect of Modifying Aggregate Surface by Micronized Calcium Carbonate on Increasing the Moisture Resistance of Asphalt Mixtures", Periodica Polytechnica Civil Engineering, 63(1), pp. 63-76, 2019. https://doi.org/10.3311/PPci.11632

[13] Cai, J., Pan, J. "Using Calcium Carbonate Whisker in Engineered Cementitious Composites", presented at: Proceedings of the 9th International Conference on Fracture Mechanics of Concrete and Concrete Structures, Berkeley, CA, USA, May 29-June 1, 2016. [online] Available at: http://framcos.org/FraMCoS-9/FullPapers/31.pdf [Accessed: 20 december 2019]

[14] Yang, Y., Deng, Y. "Mechanical properties of hybrid short fibers reinforced oil well cement by polyester fiber and calcium carbonate whisker", Construction and Building Materials, 182, pp. 258$272,2018$.

https://doi.org/10.1016/j.conbuildmat.2018.06.110

[15] Li, B., Liang, W., He, Z. "Study on high-strength composite portland cement with a larger amount of industrial wastes", Cement and Concrete Research, 32(8), pp. 1341-1344, 2002. https://doi.org/10.1016/S0008-8846(02)00804-9

[16] Wu, Z. W. "Environmental friendly high-effect cement-based materials", Concrete, 6, pp. 3-6, 1996. 
[17] Ding, Z., Zhang, D., Wang, X. "The Development and Actuality of Composite Cements in China", Cement, 3, pp. 1-5, 1997.

[18] Bin, X., Guangbo, L. "Effect of Combined Fibres on Properties of Concrete", Low Temperature Architecture Technology, 6, pp. 92-93, 2007. (in Chinese)

[19] Ramesh, M. "Flax (Linum usitatissimum L.) fibre reinforced polymer composite materials: A review on preparation, properties and prospects", Progress in Materials Science, 102, pp. 109-166, 2018. https://doi.org/10.1016/j.pmatsci.2018.12.004

[20] Piekarczyk, J., Piekarczyk, W., Blazewicz, S. "Compression strength of concrete cylinders reinforced with carbon fiber laminate", Construction and Building Materials, 25(5), pp. 2365-2369, 2011. https://doi.org/10.1016/j.conbuildmat.2010.11.035

[21] Kang, S. H., Ahn, T.-H., Kim, D. J. "Effect of grain size on the mechanical properties and crack formation of HPFRCC containing deformed steel fibers", Cement and Concrete Research, 42(5), pp. 710-720, 2012

https://doi.org/10.1016/j.cemconres.2012.02.011

[22] Li, M., Liu, M., Yang, Y., Li, Z., Guo, X. "Mechanical properties of oil well cement stone reinforced with hybrid fiber of calcium carbonate whisker and carbon fiber", Petroleum Exploration and Development, 42(1), pp. 104-111, 2015. https://doi.org/10.1016/S1876-3804(15)60012-X

[23] Kim, H. K., Nam, I. W., Lee, H. K. "Enhanced effect of carbon nanotube on mechanical and electrical properties of cement composites by incorporation of silica fume", Composite Structures, 107, pp. 60-69, 2014.

https://doi.org/10.1016/j.compstruct.2013.07.042

[24] Chakraborty, S., Kundu, S. P., Roy, A., Basak, R. K., Adhikari, B., Majumder, S. B. "Improvement of the mechanical properties of jute fibre reinforced cement mortar: A statistical approach", Construction and Building Materials, 38, pp. 776-784, 2013. https://doi.org/10.1016/j.conbuildmat.2012.09.067
[25] Wang, J.-Y., Chia, K.-S., Liew, J.-Y. R., Zhang, M.-H. "Flexural performance of fiber-reinforced ultra lightweight cement composites with low fiber content", Cement and Concrete Composites, 43, pp. 39-47, 2013.

https://doi.org/10.1016/j.cemconcomp.2013.06.006

[26] Sawsen, C., Fouzia, K., Mohamed, B., Moussa, G. "Optimizing the formulation of flax fiber-reinforced cement composites", Construction and Building Materials, 54, pp. 659-664, 2014. https://doi.org/10.1016/j.conbuildmat.2013.12.038

[27] Ministry of Construction of the People's Republic of China "GB/ T50081 Standard for Test Method of Mechanical Properties on Ordinary Concrete", China Standard Publishing House: Beijing, China, 2002. (in Chinese)

[28] Ministry of Construction of the People's Republic of China "GB/ T2419 Test method for fluidity of cement mortar", China Standard Publishing House: Beijing, China, 2005. (in Chinese)

[29] Ministry of Construction of the People's Republic of China "JGJ/ T70 Standard for test method of performance on building mortar", Beijing, China, 2009.(in Chinese)

[30] Ministry of Construction of the People's Republic of China "GB/ T17671 Method of testing cement-determination of strength", ISO, Architecture \& Building Press; Beijing, China, pp. 80-81, 1999.

[31] Ministry of Construction of the People's Republic of China "CECS13:2009 Standard test methods for fiber reinforced concrete", China Press, Beijing, China, 2009. (in Chinese)

[32] ACI Committee "ACI544-2R Measurement of properties of fiber reinforced concrete", ACI Committee, Farmington Hills, MI, USA, 544, 1999 